\title{
CONCEPÇÕES DE PROFESSORES SOBRE A INCLUSÃO ESCOLAR DE ALUNOS COM DISTÚRBIOS NEUROMOTORES
}

\author{
CONCEPTION OF TEACHERS ON SCHOOL INCLUSION \\ OF STUDENTS WITH NEUROMOTOR DISORDERS \\ LA CONCEPTION DE MAÎTRES SUR L'INCLUSION \\ DES ÉLÈVES AVEC DES DÉFICIENCES NEUROMOTRICES \\ CONCEPCIONES DE PROFESORES SOBRE LA INCLUSIÓN \\ ESCOLAR DE ALUMNOS CON DISFUNCIONES NEUROMOTORAS
}

\author{
Paulo França Santos * \\ Silviane Bonaccorsi Barbato **
}

\section{RESUMO}

Buscou-se neste trabalho identificar e analisar as concepçôes de professores sobre a inclusão escolar de alunos com distúrbios neuromotores. Doze professores de escolas regulares participaram de entrevistas semi-estruturadas individuais conduzidas por um professor hospitalar sobre o processo ensino-aprendizagem de alunos com distúrbios neuromotores. Os dados, gravados e transcritos, foram submetidos a uma análise temática dialógica, permitindo a compreensão dos enunciados. As concepçôes dos professores enfocaram os temas: a) diagnóstico; b) tratamento; c) desenvolvimento-aprendizagem. Foram enunciados significados denotando o embate entre modelos antigos e novos sobre desenvolvimento e aprendizagem de alunos com necessidades especiais. Os resultados indicaram que, segundo os participantes, a relação de cooperação estabelecida entre os professores regulares e o professor hospitalar contribui para a compreensão do processo de inclusão escolar dos alunos, bem como o esclarecimento de dúvidas e questōes sobre diagnósticos, tratamentos e mediaçōes.

Palavras-chave: Inclusão escolar. Concepções de professores. Reabilitação. Professores hospitalares. Distúrbios neuromotores.

* Doutor em Psicologia pela Universidade de Brasília (2007). Professor Hospitalar, Rede Sarah de Hospitais de Reabilitação, Salvador - BA - Brasil (pfrancaster@gmail.com).

** Doutora em Psicologia pela Universidade de Brasília (1997). Professora Adjunto III, Departamento de Psicologia Escolar e do Desenvolvimento, Instituto de Psicologia, Universidade de Brasília - DF - Brasil (barbato.silviane@gmail.com).

Agradecimentos: ao Hospital Sarah de São Luís - MA, uma das Unidades da Rede Sarah, pelo apoio institucional, e aos professores das escolas onde estudavam os pacientes em acompanhamento com os professores hospitalares, bem como suas famílias, por aceitarem participar da pesquisa. O projeto de pesquisa foi autorizado pela Diretoria da Unidade de São Luís e o texto foi aprovado para publicação pelo Comitê Científico da Rede Sarah de Hospitais de Reabilitação com sede em Brasília - DF. 


\section{INTRODUÇÃO}

A perspectiva sócio-histórica da psicologia tem procurado compreender as formas como diferentes grupos e indivíduos se apropriam de novos conceitos e atividades, considerando as influências da história e da cultura no desenvolvimento humano e na aprendizagem (LEE; MAGORINKSLY, 1995; VIGOTSKI, 1998; WERTSCH, 1993). Este trabalho enfoca a construção de significados de professores de crianças e adolescentes com distúrbios neuromotores que não apresentam déficit cognitivo, matriculados em escolas inclusivas e acompanhados pela equipe de professores hospitalares do Hospital Sarah, em São Luís - MA.

A proposta de inclusão de todos na rede regular de ensino é inovadora, exigindo dos professores um posicionamento comprometido, direcionado, também, para a necessidade de formação continuada. Ao considerarmos os dados disponíveis dos censos do IBGE, da Fundação Getúlio Vargas e do MEC, notamos que São Luís, sendo a capital de um dos Estados mais pobres do Brasil, apresenta uma série de desafios sócio-educacionais, dentre os quais se destaca o processo de inclusão dos alunos com necessidades especiais. Dados da Fundação Getúlio Vargas (2000) apontam que, da sua população total (5.657.552), 16,14\% apresentam algum tipo de deficiência, tendo o Censo 2000 revelado que $62,85 \%$ dessas pessoas vivem em situação de miséria. Já em 2001, o número de matrículas de alunos com deficiência em escolas regulares aumentou $9 \%$ em relação ao Censo de 1999. Porém, ao compararmos os dados do censo escolar do país com os do Estado do Maranhão, no mesmo período, realizado pelo MEC/INEP (2006), nota-se que, enquanto no Brasil houve um crescimento de $42,5 \%$ das matrículas em escolas e classes especiais entre 2002 e 2006, no Estado, o crescimento foi de 1,3\% das matrículas em escolas inclusivas.

Assim, considerando-se a necessidade atual de uma rápida democratização do processo de inclusão, tendo a maioria dos professores pouco ou nenhum conhecimento e formação pedagógica para lidar com as diferentes necessidades do ensino-aprendizagem em contextos inclusivos, torna-se imprescindível o desenvolvimento de estudos sobre os significados que os educadores estão construindo sobre a participação de alunos com diferentes necessidades especiais, em diferentes etapas da escolarização. Ball (1995) denomina os profissionais que estão em formação continuada como "professores em transição" (p. 234), pois estes adicionam novos conhecimentos, transformando as práticas pedagógicas para lidar com alunos em contextos de inclusão diferenciados, indicando a apropriação que ocorre com essa nova experiência (RIBEIRO, 2006) e o controle diferenciado que emerge desta (WERTSCH, 1993).

As pesquisas e estudos atuais consideram que os significados são construídos sob o impacto de dois processos que ocorrem no momento da experiência: o da ideologia (VOLOSINOV, 1992) e o das emoçôes (BARBATO, 2006; VALSINER, 2004). Emoção e ideologia marcam os significados e interagem com as crenças e valores individuais preexistentes, direcionando a apropriação do conhecimento de acordo com as condições do contexto social. A cognição distribuída nas atividades teórico-práticas individuais se relaciona à história cultural e às diferentes formas em que esta se faz presente na vida cotidiana (LEE; SMAGORINSKY, 1995). Assim, os processos de desenvolvimento- 
aprendizado do professor perpassam o seu fazer diário, movendo-o de posiçōes de internalizaçóes cognitivas da teoria e práticas para posiçóes transformadoras do comprometimento e geradoras de desenvolvimento. Nesse sentido, o aprendizado é um processo de embate, de conflitos gerados entre modelos individuais preexistentes e novas informações presentes nos contextos interacionais (BALL, 1995).

Neste estudo, buscou-se identificar e analisar os significados construídos pelos professores sobre o processo de inclusão, considerando-se as diferentes dúvidas e os embates entre significados históricos relacionados à exclusão e segregação e aqueles referentes à inclusão.

O cotidiano escolar oferece elementos para entender a importância dos projetos de acompanhamento da inclusão de alunos com distúrbios neuromotores e da construção conjunta de estratégias para a superação dos desafios diários, visto estar pleno de significados simbólicos. Este estudo se desenvolveu em uma situação de formação continuada em serviço, através do contato entre professores do Hospital Sarah e os professores de escolas inclusivas da cidade de São Luís - MA, por meio de contatos telefônicos, da participação de atendimentos no Hospital e principalmente de visitas periódicas às escolas onde estudavam os pacientes em processo de reabilitação. Nessas visitas, os professores discutiam e conversavam sobre os processos de ensino-aprendizagem que desencadeiam açôes de apoio e suporte para os alunos com distúrbios neuromotores.

A instituição hospitalar é responsável pelo cuidado de pessoas com doenças, embora nem sempre essa visão esteja associada à promoção da saúde. Os pressupostos que orientam a prática médica e o caráter curativo e terapêutico, característico da instituição hospitalar, por exemplo, em relação à prática de visita e observação sistemática dos pacientes, muitas vezes focalizam a saúde apenas como instrumento de cura, sem considerar os aspectos preventivos e, portanto, educativos (CAMPOS, 1995; DALTON; FORMAN, 1992). Mudar o foco de atenção e pensar o hospital como espaço de promoção de educação e a escola também como espaço de promoção de saúde é um desafio, principalmente quando consideramos que a concepção tradicional de saúde, em seu sentido estreito e biologista, contribuiu para o distanciamento entre saúde e educação como duas esferas relativamente independentes uma da outra (MITJÁNS MARTÍNEZ, 1996).

O hospital pode contribuir com a educação no sentido mais amplo, pois promove a troca e a construção coletiva do conhecimento, estando facilitadas pelo atendimento pedagógico baseado nas potencialidades individuais da pessoa enferma. Tais medidas respaldam projetos, como os das classes hospitalares e do atendimento educativo hospitalar, como alternativas que contribuem para a continuação do processo de escolarização de crianças e adolescentes hospitalizados ou em reabilitação (BARROS, 1999; FONTES; WELLER, 1998; MEDEIROS; GABARDO, 2004, SANTOS, 2000). Por isso, é importante efetivar os contatos entre o hospital e a escola, no sentido de contribuir no atendimento às crianças e adolescentes com necessidades especiais por meio do diálogo entre os professores.

Em relação ao atendimento educativo hospitalar desenvolvido pela Rede Sarah de Hospitais de Reabilitação, a atuação dos professores hospitalares, como são denominados na referida instituição, ocorre em equipe multidisciplinar. No Sarah não existem classes hospitalares e sim o atendimento educacional, que faz parte do programa amplo de 
reabilitação. Nessa instituição, seu trabalho visa à construção do conhecimento sobre a educação de adultos, crianças e adolescentes em processo de reabilitação, em conjunto com os profissionais de saúde.

O trabalho dos professores, nas unidades hospitalares presentes no país (Brasília DF, São Luís - MA, Salvador - BA, Belo Horizonte - MG, Rio de Janeiro - RJ e Macapá - AP) objetiva avaliar o desenvolvimento e a aprendizagem do paciente; acompanhar a aprendizagem e a vida escolar, ocupacional e profissional; estimular e favorecer a inserção e/ou reinserção escolar; criar estratégias e recursos alternativos para educação e/ou reeducação; favorecer a reabilitação das habilidades cognitivas; orientar a família e a escola; realizar trabalhos de pesquisa e contribuir, quanto ao enfoque pedagógico, com a equipe interdisciplinar na formulação dos programas de reabilitação (ASSOCIAÇÃO DAS PIONEIRAS SOCIAIS, 1998).

A atuação do professor hospitalar na Rede Sarah se diferencia do trabalho realizado pelos professores das classes hospitalares que objetivam atender aos alunos em situação de hospitalização. No caso do Hospital Sarah, os professores hospitalares são profissionais contratados pela própria instituição, sendo membros efetivos da equipe interdisciplinar. O trabalho, além do acompanhamento escolar e psicopedagógico, inclui também a participação em discussão de caso, interconsultas com a equipe e a formação de profissionais (APS, 1998).

Apesar das diferenças entre a atuação dos professores hospitalares da Rede Sarah e dos professores das classes hospitalares, podemos afirmar que o trabalho realizado pelos professores dos hospitais da Rede se assemelha ao que é previsto nos documentos seguintes, estando assim, em consonância com os princípios que regem o atendimento pedagógico-educacional destinado a crianças, jovens e adultos hospitalizados, assegurados pelo Ministério da Educação (BRASIL, 1994). O mesmo é apresentado no Estatuto da Criança e do Adolescente Hospitalizado (Resolução n. 41, out. 1995), segundo o qual "[...] toda criança tem direito de desfrutar de alguma forma de recreação, programas de educação para a saúde, acompanhamento do currículo escolar durante sua permanência hospitalar" (BRASIL, 1995).

\section{MÉTODO}

As entrevistas analisadas neste estudo fazem parte de um projeto de pesquisa mais amplo que objetiva analisar os significados construídos por professores e familiares sobre a inclusão escolar de alunos com distúrbios neuromotores e outras necessidades especiais. Optou-se pela metodologia qualitativa, pois esta permite um aprofundamento na análise dos dados de conversação e nos significados que regem as enunciações, referentes às relações dialógicas estabelecidas entre entrevistador e entrevistado em relação ao tema de estudo (LINELL, 2003; MARKOVA; FOPPA, 1990). É um processo complexo de construção conjunta de conhecimento, que atenta para os aspectos relevantes à exploração de um problema humano ou social, levando em consideração a relação estabelecida entre os participantes, o processo de construção e análise dos dados, além da importância dos significados (BIASOLI-ALVES, 1998; SILVA, 1998). Em psicologia do desenvolvi- 
mento, a pesquisa qualitativa prioriza a construção dos dados por meio de entrevistas e da observação (CRESWELL, 1997; MEY, 2001).

\section{I - Participantes}

Participaram 12 professores, todos eles acompanhando alunos que eram pacientes do Hospital Sarah Unidade de São Luís - MA inseridos na rede regular de ensino.

A fim de selecionar os professores, optou-se por entrevistar aqueles que trabalhavam em escolas recém tornadas inclusivas e com alunos sem déficit cognitivo. Para tanto, identificaram-se alunos que estavam em processo de inclusão e que tinham sido avaliados pelos psicólogos da equipe de reabilitação do hospital, através da Escala de Inteligência Wechsler para Crianças - WISC e Escala de Inteligência Wechsler para Adultos - WAIS, além das provas piagetianas.

Seis professores tinham curso superior, sendo dois em pedagogia (P9, P12); dois eram licenciados em letras (P10, P11), outro, em história (P4), e um terceiro, bacharel em filosofia (P4); cinco tinham cursos de magistério nível médio (P1, P2, P5, P6, P8); um deles apresentava curso superior incompleto (P6) e um outro ostentava ensino médio incompleto (P7). Além desses cursos, uma professora relatou ter curso técnico em enfermagem (P2), um professor iniciara curso de teologia (P3) e uma professora se especializara em ensino especial (P1). Esses professores estavam distribuídos em sete escolas localizadas no centro e na periferia da cidade de São Luís, sendo quatro públicas estaduais, duas comunitárias e uma cooperativa educacional.

Os professores eram responsáveis por quatro crianças entre oito e nove anos de idade, cursando a $1^{\text {a }}$ e $2^{\text {a }}$ série do Ensino Fundamental, e três adolescentes de 15 , 16 e 17 anos de idade, que cursavam respectivamente a $5^{\mathrm{a}}$ e $3^{\mathrm{a}}$ série do Ensino Fundamental e a $1^{\text {a }}$ série do Ensino Médio, distribuídos em escolas públicas, comunitárias e uma cooperativa educacional. Todos os alunos estavam matriculados, com freqüência regular e com história de repetência escolar. Desses, três alunos tinham diagnóstico de paralisia cerebral; dois de seqüela de mielomeningocele; um de tremor essencial e um de acidente vascular cerebral. Apenas um apresentava alteração na linguagem e nenhum deles apresentava déficit visual ou auditivo. Dois usavam cadeira de rodas e os demais tinham marcha independente. Três crianças apresentavam dificuldades nos membros superiores que dificultavam realização da escrita manual, necessitando de adaptações do tipo letras e numerais móveis ou utilizavam máquina de escrever ou computador.

\section{2 - Instrumentos e materiais}

Foram elaborados roteiros para as entrevistas semi-estruturadas que buscaram enfocar as percepções dos professores quanto ao processo de escolarização de crianças com distúrbios neuromotores: escolarização, o processo de ensino-aprendizagem, acompanhamento realizado pelo professor hospitalar, aspecto motor/locomotor dos alunos e diagnóstico e tratamento. Utilizou-se um gravador de fita cassete.

\section{3 - Procedimento}

Foram realizadas entrevistas semi-estruturadas com os professores, individualmente, nas próprias escolas. Cada entrevista teve uma média de 30 minutos de duração. As 
entrevistas foram transcritas em sua integridade e submetidas a uma análise dialógica temática. Nesse tipo de análise, submete-se o material a um tratamento similar ao da análise de conteúdo temática (BARDIN, 1977; KRIPPENDORF, 1980; MAYRING, 2000), porém, tendo-se como unidade de análise a enunciação, levando-se em consideração a dialogicidade e os aspectos polifônicos (LINELL, 1998), redundâncias, complementaridades e contradições, da construção do conhecimento que se dá ao longo da entrevista. Cada texto é submetido a uma leitura intensiva, buscando-se identificar os temas e subtemas. Em seguida, busca-se o que há de comum entre as várias análises que foram, então, agrupadas em temas gerais (BARBATO, 2004; MEYERS, 2000; RATNER, 2001).

\section{RESULTADOS}

Os resultados indicaram que a construção de significados dos 12 professores sobre a inclusão de crianças e adolescentes com distúrbios neuromotores se organizava a partir de três temas gerais: diagnóstico, tratamento, desenvolvimento-aprendizagem, tendo aspectos relacionados à lentidão e à postura corporal, bem como aos movimentos das crianças e adolescentes, permeado os enunciados, aproximando-os de significados relacionados às características definidoras de deficiência mental.

I) diagnóstico: dos 12 entrevistados, oito afirmaram desconhecer os diagnósticos sobre o quadro clínico apresentado por seus alunos. Ao discorrerem sobre o assunto faziam descrições sobre as crianças quanto às alteraçôes físicas, demonstrando dúvidas quanto aos aspectos cognitivos, relacionando-os ao comportamento da criança, como, por exemplo, lentidão, dispersão, expressōes faciais diferenciadas, manutenção da boca aberta; se referiam aos alunos utilizando rótulos como "lerdo", "doente", "tortinho". Houve uma tendência a associar os distúrbios neuromotores com a deficiência mental e os estereótipos do tipo: "só sacode a cabeça", "é uma pessoa estranha", "tem problema mental", comportamentos esses geralmente atribuídos a alunos seriamente comprometidos intelectualmente.

2) tratamento: apesar de manterem contatos regulares com os professores hospitalares, observou-se que os professores das escolas afirmavam desconhecer o tratamento de reabilitação dos seus alunos e, mesmo quando afirmavam conhecê-lo, observou-se a recorrência de crenças na cura das patologias crônicas apresentadas por seus alunos; os significados produzidos pelos professores sobre a reabilitação incluíam a preocupação com a intervenção e prognóstico com expectativa de cura, mesmo tendo sido esclarecido, tanto pelo professor hospitalar, quanto pela equipe do hospital, que as seqüelas físicas e motoras decorrentes das lesões sofridas pelos alunos seriam permanentes.

3) desenvolvimento-aprendizagem: neste tema, as enunciações incluíram a prática pedagógica e o desenvolvimento típico e atípico; planejamento e recursos pedagógicos, como a condução e avaliação em relação ao desenvolvimento atípico; comparações entre desenvolvimento infantil típico e atípico, avaliando positivamente, como importantes e mediadoras, as visitas dos professores hospitalares à escola. Os professores apontaram suas dificuldades para lidar com a criança ou o adolescente em sala de aula, relacionandoas, também, a problemas de formação docente. Os professores demonstraram recorrentes dúvidas em relação aos distúrbios neuromotores, enunciados como uma lentidão no 
aprender, mesmo que os alunos em questão não apresentassem atraso cognitivo. Por outro lado, foram enunciados significados referentes às potencialidades de aprendizagem, assim como experiências positivas direcionadas para a construção da inclusão, com a superação de preconceitos.

\section{DISCUSSÃO}

A reflexão sobre o diagnóstico de deficiências ou patologias suscita questōes relacionadas aos rótulos que são atribuídos às pessoas com necessidades especiais. Muitos profissionais defendem a idéia de que o diagnóstico não é um aspecto relevante na área educacional, embora, ao discorrerem sobre o assunto, apresentem dúvidas e questionamentos que, de certa forma, comprometem seu entendimento sobre os reais problemas e dificuldades de seus alunos. Observou-se que, ao falarem sobre suas práticas pedagógicas, associavam-nas, geralmente, a crenças e aos valores sobre a educabilidade de pessoas com necessidades especiais historicamente estabelecidas. Tais atitudes podem contribuir para elaboração de interpretaçôes feitas pelos professores sobre o comportamento de seus alunos com distúrbios neuromotores que, muitas vezes, não correspondem à realidade dos fatos. No caso de deficiências que sejam marcadas no corpo e no movimento das crianças, é importante que os professores estejam informados e conheçam o diagnóstico, para poder lidar com os estigmas historicamente arraigados. Houve descrições em que professores afirmaram ter visto a criança "babar" diversas vezes, mesmo que o aluno não apresentasse sialorréia.

Os estereótipos permanecem, também, porque alguns significados e conceitos complexos estão presentes recorrentemente e circulando no nosso cotidiano. Há, por exemplo, práticas históricas na própria medicina, em que, ao definir o diagnóstico de um paciente, muitas vezes os profissionais tendiam a apresentar um determinado quadro clínico, como se o paciente "portador de alguma patologia" representasse ou fosse a própria doença, reforçando o estereótipo. Ainda hoje é comum ouvir nos corredores dos hospitais os médicos dizendo: "Como vai o lesado medular, ou o PC (paralisia cerebral), do leito tal" (SANTOS, 2000).

Quando se desconhece algo, recorre-se a conhecimentos embasados em crenças histórico-culturalmente transmitidas, aos cânones da cultura (BRUNER, 1997); a partir de conhecimentos intuitivos, constroem-se narrativas para explicar o novo, ou buscamse recursos na fala do outro. Ao ser questionada sobre o diagnóstico de sua aluna, uma professora respondeu:

P6: Olha, a mãe dela já me explicou um pouquinho, que é um problema na medula, parece que é na medula, e que por isso ela não conseguia andar, mas se fizer uma terapia, uma coisa assim... ela não me explicou direito.

Ao se referir a um aluno com paralisia cerebral, outro professor enunciou:

P3: Eu não sei o que ele tem. Eu até desconfiava da maneira dele olhar, o semblante dele... fica todo o tempo de boca aberta, eu já tinha desconfiado dessa deficiência dele. 
Observamos como P3 não consegue identificar as características da patologia da criança, nem consegue dar informaçóes associadas ao diagnóstico a partir da convivência diária com seu aluno, mencionando a deficiência num sentido genérico e descontextualizado, provavelmente associada ao estereótipo de pessoa com deficiência mental, reproduzida, por exemplo, inúmeras vezes no cotidiano da cultura em imagens diferenciadas, muitas vezes com cunho grotesco. P3 não relacionou a descrição que fez do aluno ao seu quadro clínico.

A professora $\mathrm{P} 12$, ao se referir à aluna com tremor essencial, caracterizado basicamente por alteração na coordenação dos movimentos, comentou:

P12: Eu não sabia do problema mental dela quando veio aqui, a gente ficou sabendo apenas por acaso. Uma professora me falou que nós temos que ver e estudar o caso dessa aluna, pois ela está com um problema de coordenação motora. (...) Olha, em relação aos movimentos, é como se ela fosse realmente uma pessoa defeituosa fisicamente. Porque, com a continuação do tratamento, ela vai melhorando, ela vai adquirindo a coordenação motora. Na verdade, eu não sei dizer exatamente o que [ela] está fazendo para recuperar essa coordenação.

O desconhecimento sobre as características do quadro apresentado pelos alunos é motivo de confusão, tanto para compreensão do caso como para a intervenção. P12 revela desconhecimento a ponto de não conseguir relacionar um sintoma com outro. De fato, a dificuldade na coordenação motora não está diretamente associada ao retardo mental; no entanto, recorrentemente os professores entrevistados associaram os problemas motores com o retardo mental. Isso pode indicar o quanto o olhar do professor muitas vezes volta-se apenas para um aspecto do diagnóstico baseado no senso comum, no que é mais freqüentemente veiculado no cotidiano, construído por processos intuitivos a partir de crenças e valores historicamente presentes na cultura (VALSINER; BRANCO; DANTAS, 1997). O sentido que o uso de termos como "deficiência" e "defeituosa" adquirem nas enunciaçôes, considerando-se a seqüência de construção de significados pelas entrevistadas, está direcionado para aspectos historicamente relacionados à segregação (AMARAL, 1995; MENDES, 2002). No entanto, ao mencionar a necessidade de uma maior compreensão do diagnóstico, P12 demonstra um movimento em direção a uma nova concepção, que desemboca, porém, numa possível expectativa de cura ou melhora substancial a partir de um tratamento para recuperar a coordenação motora.

Os professores citados anteriormente revelam desconhecimento em relação ao diagnóstico dos seus alunos. Observamos, também, que existem aqueles que, mesmo afirmando conhecer aspectos do diagnóstico, não conseguem explicar ou, então, tentam construir explicaçôes a partir do que experienciam no seu cotidiano, quando observam os avanços e retrocessos dos seus alunos. Vejamos na fala de P1 um exemplo das crenças sobre o desenvolvimento, quando o desconhecimento sobre o diagnóstico dificulta uma intervenção mais coerente:

P1: Quando ela fazia o terceiro período, eu sempre ia na sala da professora, ela contava que [a aluna] teve um problema; ela nasceu boazinha, então ingeriu soda cáustica e isso afetou sua coordenação motora e não o cérebro; mas ela conseguia fazer as atividades dela em dia e, nisso, ela foi aprovada para a primeira. Eu sempre vou na sala de todas as crianças e adolescentes aqui. 
Segundo informações obtidas nos registros dos atendimentos realizados no hospital, a criança em questão foi reprovada uma vez na primeira série por apresentar dificuldades motoras, mesmo depois de ser alfabetizada. Com a lesão no cérebro, a criança começou a apresentar uma incoordenação motora nos membros superiores como seqüela, dificultando a legibilidade de sua escrita. Esse fato, provavelmente, foi relacionado por P1 às crenças e práticas tradicionais de alfabetização, para as quais a coordenação motora é condição básica para a aprendizagem da escrita, influenciando a tomada de decisão que resultou na reprovação da aluna. De acordo com a sequiência dos significados produzidos em sua entrevista, supõe-se que a professora procurava explicações a fim de poder entender como, apesar da incoordenação motora, a aluna fazia as tarefas em dia, conseguindo ser aprovada para a segunda série.

Constatou-se que, além das crenças sobre a aprendizagem, também são concretizados outros elementos nos discursos dos professores que indicaram as dificuldades encontradas em conhecer os diagnósticos de seus alunos e, assim, encontrar meios viáveis para superação das dificuldades e resolução dos problemas. Por isso, não basta apenas esclarecer o diagnóstico, é preciso assumir uma posição de co-construtores de uma relação na qual os alunos sejam participantes ativos e não sejam vistos sob o prisma de crenças e valores característicos dos processos segregatórios.

A construção de novos conhecimentos se faz necessária para que se compreenda que, por exemplo, uma criança que sofreu uma lesão cerebral pode estudar numa classe regular, mesmo que para isso necessite de adaptações curriculares. Nesse sentido, destacamos a importância do trabalho conjunto escola-hospital, para a construção de instrumentos necessários para desenvolver uma atuação junto aos alunos, a partir do esclarecimento do diagnóstico, do tratamento e mesmo das intervençôes indicadas para cada caso.

P6: Eu não sei que tipo de tratamento ela faz, talvez seja fisioterapia, eu acho que é isto. Eu acho que ela pode até, talvez, caminhar de muletas, pode até ser, né? Se fizer uma fisioterapia, porque a mãe disse que ela anda um pouquinho, parece, eu não sei se é de muleta, uma coisa assim. "É porque ela nunca conversou muito comigo em relação ao problema de [aluna]".

P6 constrói recorrentemente suposições sobre o tratamento baseadas em conversas que teve com a mãe da aluna e também nas conversas possivelmente obtidas com o professor hospitalar. Além disso, a convivência diária com a criança na escola poderia ajudála a compreender melhor sua aluna; porém, P6 não menciona suas observações sobre a criança como fonte para suas enunciações. Pensamos que o processo de construção conjunta e contínua de conhecimento possa ser um caminho para superação das dificuldades (VIGOTSKI, 1995; 1998).

É na zona de desenvolvimento proximal que se efetivam as trocas de saberes, os esclarecimentos de dúvidas e as contribuiçôes de cada um para a superação dos obstáculos. Os resultados, no entanto, revelam a necessidade de se criar novas estratégias que proporcionem a reflexão dos professores sobre as crenças que intervêm em suas aprendizagens. Nesse sentido, observa-se que, por meio do acompanhamento e da formação continuada de professores, são oportunizadas discussóes nas quais sejam respeitadas suas experiências acumuladas. E, a partir dessa prática, eles podem transformar suas ações, sem repetir com 
seus alunos os caminhos que pensam ter percorrido em sua experiência na cultura e no ambiente escolar. Desse modo, os professores podem desenvolver técnicas e estratégias pedagógicas pautadas em referenciais teóricos, sem depender apenas de suas habilidades para o mero acolhimento dos alunos na sala de aula. A necessidade de acompanhamentos sistemáticos e de cursos de formação continuada é premente, pois os resultados deste estudo indicam uma busca por recursos e meios ainda pautados no senso comum para obterem as informaçōes (ENUMO, 1989; FERREIRA; SOUZA; NUNES; MENDES; GLAT, 2002). Em alguns casos, o professor recorre a contribuições deixadas pelos seus pares, ou seja, outros professores da própria escola.

Observou-se que alguns enunciados revelam que nem sempre os professores compreendem as limitações dos seus alunos. P6, por exemplo, usa freqüentemente a expressão "coordenação motora" referindo-se às prováveis dificuldades de aprendizagem das crianças, denotando que desconhece o diagnóstico, bem como o tratamento recebido no hospital. Talvez por esse motivo, e por não conseguir perceber os avanços acadêmicos dos alunos, a participante tenha verbalizado ainda precisar de mais informações para poder construir uma explicação sobre sua aluna:

P6: A professora do ano passado me contou que [a aluna] fazia um tratamento lá no Sarah. Eu acredito ser assim uma terapia quanto à coordenação motora e também informações sobre a série que ela está cursando.

Ao longo das entrevistas, pode-se perceber que os professores das escolas apresentaram dificuldades para relembrar os conhecimentos sobre diagnósticos, tratamento e ferramentas mediacionais para o aprendizado trabalhado com os professores hospitalares. Esse jogo de contrastes demonstra as dificuldades encontradas na construção do conhecimento, uma vez que indicam o embate entre os modelos preexistentes e as novas informações (BALL, 1995). Um outro conceito que pode nos ajudar a explicar esse fenômeno encontrado nas enunciaçoes, que denotam um forte embate entre o novo e o conhecimento adquirido anteriormente pelos professores, foi desenvolvido por Bakhtin (1992) quando defende a dinâmica dialética entre as forças centrípetas (de permanência) e as forças centrífugas (de inovação) do desenvolvimento humano. $\mathrm{O}$ embate entre o novo e o conhecido anteriormente, com o tempo e o direcionamento efetivo da negociação de significados, resulta na transformação do conhecimento (VIGOTSKI, 1989).

A partir da definição do tema desenvolvimento e aprendizagem, observa-se como os demais temas se integram para formar um painel geral das diferentes perspectivas sobre o aluno com distúrbios neuromotores no contexto escolar. Algumas enunciaçóes, por exemplo, apontam para a questão da metodologia utilizada em sala de aula, apesar de nem sempre explicitar qual linha teórica orienta o fazer pedagógico.

P12: Aqui, na nossa escola, cada professor tem a sua metodologia. Não temos nenhum tipo de treinamento para os professores. No planejamento mensal, falamos sobre a sistemática de trabalho, discutimos como a gente vai funcionar cada mês, o que vai acontecer...

Diante da falta de uma definição metodológica, alguns professores procuram criar 
rotinas a fim de alcançarem os objetivos estabelecidos no programa pedagógico da escola.

P7: Eu converso demais com os meus alunos, eu falo sobre a violência, sobre meninos de rua, eu dou muitos exemplos para eles. Às vezes, na minha aula, fazemos exercícios, dou leitura, faço ditado de palavras e também tomo tabuada, porque a cada dia trabalhamos uma matéria, uma disciplina.

Outros professores sinalizaram a relação entre deficiência e aprendizagem, porém enunciando quase sempre a idéia de que o aluno é lento, que apresenta dificuldade para aprender, enfatizando freqüentemente esses pontos e relacionando a interpretação que construíram até o momento, sobre o diagnóstico, com as dificuldades dos seus alunos. Os professores deixaram transparecer a idéia de que um aluno, considerado "lento", por apresentar alteraçóes nos movimentos, parecia apresentar também retardo mental, não conseguindo estabelecer a diferença entre o déficit motor e o déficit cognitivo.

P3: Quando ele aprende, quando ele assimila, ele rende. Eu percebo que, de problema, é apenas o fato dele ser lento para aprender, não que ele não aprenda, mas é que ele é lento em relação aos outros alunos. Essa é a única diferença que ele tem. Fora isso, eu não percebo nenhuma outra.

Outros enunciados indicam que os professores reconhecem, em certos momentos ("quando ele aprende"), que há um aprendizado em andamento, porém enfatizam a lentidão comparando o aluno com distúrbios neuromotores, colocando-o "em relação aos outros alunos", tentando normalizá-la por meio do seu discurso - "fora isso não percebo nenhuma outra [diferença]". Nota-se, no entanto, que seu esforço ainda está em contraste com a crença de que ser lento não é o mais adequado, e que a lentidão em nossas escolas está, geralmente, associada a estilos de aprendizagem de crianças rotuladas como deficientes mentais e às ferramentas mediadoras, atualmente disponibilizadas aos alunos, por exemplo. Mais uma vez é evidenciado o embate entre as novas informaçóes e as anteriores, baseadas numa crença de fundo que parece estabelecer uma relação direta entre distúrbios neuromotores e a deficiência mental ("é lento"; "não acompanha as tarefas"; "fica com a boca aberta"), embora, no caso dos sujeitos em questão, tal relação não se aplique.

As consideraçôes dos professores sobre a diferença parecem estar somente na maneira dos seus alunos aprenderem. Suas enunciações no geral enfatizam a relação distúrbio neuromotor-deficiência mental. No entanto, são feitas ponderações sobre a ocorrência de aprendizagem contínua, "de aproveitamento regular", embora o professor ainda tenha dificuldade para explicar como tal processo ocorra. Mesmo assim pode-se perceber que o professor possivelmente considere e observe as potencialidades dos alunos, mesmo que "ele seja diferente para aprender" e que "hoje não tenha mais essa coisa de discriminar", como verbaliza P5.

P5: Para mim, não tem diferença ter um aluno deficiente em sala de aula, mas, no começo do ano, eu percebi que ele era um pouco estranho, o jeito dele sorrir, de falar, era engraçado para 
os outros alunos, mas ele superava. Hoje não tem mais essa coisa de discriminar. A questão é que ele é lento, mas ele no momento assimila tudo. Ele é um aluno de aproveitamento regular. Você olha para ele e percebe a diferença, ele é diferente para aprender, fora isso aí, eu não percebo nenhuma diferença dele em relação aos outros alunos.

P5, por sua vez, recorre à discussão sobre ética para demonstrar o embate atual, próprio do momento de transição (BALL, 1995; RIBEIRO, 2006), entre duas posições: “esse, não vamos aceitar" e "ele é igual a qualquer outro".

P5: É uma experiência que a gente precisa ter, né? É diferente, porque a gente vai conhecer como é aquele aluno, o desempenho dele. Não vejo problema nenhum ter uma criança deficiente na sala, para mim é uma satisfação poder ajudar. Acho necessário que o professor tenha consciência de que, quando uma pessoa existe, ela tem que ter carinho. Nós, enquanto professores, vamos nos deparar com qualquer tipo de situação, então nós estamos preparados, nós temos a ética profissional, nós temos que ter ética de professor, de chegar e encarar o aluno, encarar, eu digo, é aceitar o aluno, não podemos dizer "esse eu não vou aceitar", vou discriminar. Ele é igual a qualquer outro.

Ter um aluno com necessidades especiais em sala de aula põe em evidência uma série de conflitos, pois não se trata de comparar alunos ou normalizá-los. A inserção da criança deficiente no ambiente escolar coloca no processo de inclusão o professor e as outras crianças: uma vez necessitando lidar com essa nova informação, cabe ao professor mediar a inclusão da criança na turma e a turma à criança.

Para Vigotski (1995), o desenvolvimento de uma criança diferente é único. Para atingir o mesmo nível de desenvolvimento de uma criança com desenvolvimento típico, a criança com necessidades especiais percorre um caminho diferente, utilizando outros meios e as ferramentas mediacionais de forma diferenciada. Cabe aos profissionais da educação considerar as possibilidades singulares de cada criança, atentando para o que ela já conhece e o que pode fazer sozinha, seu nível de desenvolvimento real. Pois é o educador quem vai construir, em conjunto com seus alunos, as estratégias de compensação. Não se supera um problema sem tomar consciência dele; isso pode ser aplicado tanto para o aluno, quanto para o professor. À medida que os professores têm oportunidades de refletir sobre esse fato, podem transformar suas práticas pedagógicas pelo conhecimento, teoricamente, sem simplificar suas atitudes diante dos problemas encontrados (COLLARES, 1992).

Em linhas gerais, a percepção dos professores sobre a inclusão escolar de alunos com distúrbios neuromotores está relacionada, de certa forma, com seu processo de formação. Tal constatação permite compreender como os professores de escolas regulares constroem não somente suas representações sobre as crianças e adolescentes, como também sua atuação diante das situações vivenciadas no contexto a partir de valores e crenças historicamente constituídos.

Nesse sentido, torna-se evidente a importância da relação entre os professores e os alunos, mediada pelo trabalho conjunto entre hospital e escola. Assim, os contatos estabelecidos entre os professores das escolas e o professor hospitalar possibilitarão as mediações 
necessárias para a construção do conhecimento. De acordo com suas enunciações, essa relação contribuiu para a compreensão do processo de ensino-aprendizagem.

\section{CONCLUSÕES}

Neste estudo, buscou-se identificar e analisar os significados construídos pelos professores sobre o processo de inclusão de seus alunos com distúrbios neuromotores, considerando-se as diferentes dúvidas e os embates entre significados históricos relacionados à exclusão e segregação e aqueles referentes à inclusão. Os resultados da análise dialógica temática indicaram que a construção de significados dos 12 professores foi organizada em três temas gerais, tendo sido permeada recorrentemente por aspectos relacionados ao ritmo, à postura corporal e aos movimentos das crianças e adolescentes: os indicadores físico-motores e de lentidão que os professores relataram tinham significados relacionados com os usualmente utilizados para definir características de deficiência mental.

Tendo-se observado o embate entre modelos anteriores e os novos modelos apresentados pela educação inclusiva e pela mediação dos professores hospitalares ao longo da entrevista, conclui-se que estes são característicos de períodos de transição próprios de construçōes de conhecimento em novas zonas de desenvolvimento proximal.

O contato do hospital com a escola ajuda a construir uma relação de troca, por meio da qual os professores complementam e transformam seus conhecimentos acerca da criança e da forma de atuação com elas. As enunciações são ricas em informações e depoimentos que fortalecem o processo dialógico (VOLOSINOV, 1992), e o embate das várias vozes presentes nos diálogos entre os professores configura a busca de alternativas e estratégias para a solução de problemas. Assim, as dúvidas e os questionamentos dos professores evidenciados podem produzir elementos necessários para a mudança de atitudes e práticas.

Porém, deve-se considerar que problemas referentes à formação dos professores são incrementados, também, por fatores como a falta de recursos nas escolas, pois muitas vezes os professores têm claros os objetivos, mas falta uma integração destes com os demais aspectos que envolvem o processo de ensino-aprendizagem, que vão desde a existência de materiais didático-pedagógicos e mediações adequadas até a definição de projetos educacionais capazes de atender as necessidades dos educadores e dos alunos. A aceitação do uso de instrumentos mediadores atuais em sala, a adaptação e criação de novos procedimentos passa, também, pela compreensão do processo de inclusão enquanto política pública.

Sendo assim, a construção de conhecimento sobre a inclusão de crianças e adolescentes com distúrbios neuromotores não acontece de forma linear, mas a partir do embate de saberes e de conflitos entre os novos e antigos conhecimentos sobre como se dão os processos de desenvolvimento-aprendizado nas escolas inclusivas. Considerando-se os resultados deste estudo e outros fatores mencionados neste texto, torna-se importante que os processos de formação continuada contemplem em suas propostas itens referentes ao uso e criação de ferramentas mediadoras que estimulem a participação ativa das crianças e os aspectos do diagnóstico e tratamento, possibilitando ao professor compreender os estilos e as potencialidades de aprendizagem de seus alunos com distúrbios neuromotores. 


\section{Referências}

AMARAL, Lígia Assumpção. Conhecendo a deficiência (Em companhia de Hércules). São Paulo: Robe Editorial, 1995.

ASSOCIAÇÃO DAS PIONEIRAS SOCIAIS. Relatório anual das atividades da Rede Sarah de Hospitais do Aparelho Locomotor. Brasília: APS, 1998.

BAKHTIN, Mikhail Mikhailovich. Estética da criação verbal. Trad.: Maria Ermantina G. Pereira. São Paulo: Martins Fontes, 1992.

BALL, Arnetha. Teachers' developing philosophies on literacy and their use in urban schools. In: LEE, Carol; SMAGORINSKY, Peter (Orgs.). Vygotskian perspectives on literacy research. Cambridge: Cambridge University Press, 1995. . p. 1-18

BARBATO, Silviane Bonaccorsi. Migration, memory and exclusion: a study on new identity formation in rural settlements in the Federal District, Brazil. XIII International Oral History Conference. Memory and Globalization, 2004. Anais, Roma. p. 1-7.

. Dialogical self in narratives: historical multivoicedness, cultural multivoicedness. In: 4th In ternational Conference for the Dialogical Self, 2006, Braga, Portugal. Anais 4th International Self. Braga: Universidade do Minho, 2006. v. 1. p. 76-76.

BARDIN, Laurence. Análise de conteúdo. Lisboa: Ediçōes 70, 1977.

BARROS, Alessandra. Soares. A prática pedagógica em uma enfermaria pediátrica: contribuiçōes da classe hospitalar à inclusão desse alunado. Revista Brasileira de Educação, São Paulo, v. 12, p. 84-93, 1999.

BIASOLI-ALVES, Zélia Maria Mendes. A pesquisa em Psicologia - Análise de métodos e estratégias na construção de um conhecimento que se pretende científico. In: ROMANELLI, Geraldo; BIASOLIALVES, Zélia Maria Mendes (Orgs.), Diálogos metodológicos sobre prática de pesquisa. Ribeirão Preto: Legis Summa, 1998. p. 135-157.

BRASIL. Ministério da Educação - SEESP: Política Nacional de Educação Especial. Educação Especial: um direito assegurado. Livro 1. 1994.

. Ministério da Justiça. Direitos da Criança e do Adolescente Hospitalizados. Resolução n. 41, D. O. U., n. 199, 1995.

BRUNER, Jerome. Atos de significação. Trad.: S. Costa. Porto Alegre: Artmed, 1997.

CAMPOS, Terezinha Calil Padis. Psicologia hospitalar. a atuação do psicólogo em hospitais. São Paulo: EPU, 1995.

COLLARES, Cecília Azevedo Lima. Preconceitos no cotidiano escolar: ensino e medicalização. Campinas: Cortez, 1992.

CRESWELL, John. Qualitative inquiry and research design: choosing among five traditions. London: Sage Publications, 1997.

DALTON, Richard; FORMAN, Mark. Psychiatric hospitalization of school-age children. London: American Psychiatric Press, 1992.

ENUMO, Sonia Regina Fiorim. Deficiência Mental: A problemática formação de professores no Estado de São Paulo. Ciência e Cultura, São Paulo, v. 12, n. 42, p. 1.225-1.229, 1989.

FONSECA, Eneida Simōes. Classe hospitalar no Brasil. In: Congresso ibero-americano de educação especial, Paraná. Anais, Brasília: Qualidade. v. 2, 1998. p. 323-327. 
FONTES, Rejane Sousa; WELLER, Liliana Hochman. Classe hospitalar: não interrompendo o processo de escolarização. In: Congresso ibero-americano de educação especial, 3. Paraná. Anais, Brasília: Qualidade, 1998. p. 368-372.

FUNDAÇÃO GETÚLIO VARGAS Retratos da deficiência no Brasil. [On-line] 2003. Disponível em: <www.fgv.br/cps/deficiencia_br/PDF/PPD_Sumario_Executivo.pdf>. Acesso em: 15 mai. 2007. KRIPPENDORF, Khus. Content analysis. Londres: Sage, 1980.

LEE, Carol; SMAGORINSKY, Peter. Constructing meaning through collaborative inquiry. In: (Orgs.). Vygotskian Perspectives on literacy research. p. 1-18. Cambridge: Cambridge University Press, 1995.

LINELL, Per. Approaching dialogue. Amsterdam: John Benjamins, 1998. What is dialogism? Disponível em: <www.Google/scholar>. Acesso em: 17 jan. 2005.

LUBER, Raymond. Partial hospitalization: a current perspective. New York: Plenum Press, 1979. MARKOVÀ, Ivana; FOPPA, Klaus. The dynamics of dialogue. London: Harvester Wheatsheaf, 1990.

MAYRING, Philipp. Qualitative content analysis. Fórum: Qualitative Social Psychology, Budapest, v. 1, n. 2, p. 1-10. Disponível em: <www.qualitative-research-net>. Acesso em: 17 jan. 2005.

MEDEIROS, José Gomes; GABARDO, Andréia Ayres. Classe hospitalar: aspectos da relação professor-aluno em sala de aula de um hospital. Interação em Psicologia, Curitiba, v. 8, n. 1, p. 67-79, 2004.

MENDES, Enicéia Gonçalves; NUNES, Lelia de Paula; FERREIRA, Julio Romero; GLAT, Rosana. Análise das dissertações e teses sobre Educação Especial nas áreas de Educação e Psicologia. In: MARQUEZINE, Maria Cristina; ALMEIDA, Maria Amélia; OMOTE, Sadao (Orgs.), Colóquios sobre Pesquisa em Educação Especial. Londrina: Eduel, 2003. p. 137-152.

MEY, Günter. Qualitative research and the analysis of processes. Considerations towards a "qualitative Developmental Psychology”. Fórum: Qualitative Social Psychology, Budapest, v. 1, n. 1, p. 1-18. Disponível em: <www.qualitative-research-net>. Acesso em: 17 jan. 2005.

MITJÁNS MARTÍNEZ, Albertina. La escuela: un espacio de promoción de salud. Psicologia Escolar e Desenvolvimento, Campinas, v. 1, n. 1, p. 19-24, 1996.

MYERS, Greg. Análise da conversação e da fala. In: BAUER, Martin; GASKELL, George. (Orgs.). Pesquisa qualitativa com texto, imagem e som: um manual prático. Trad.: Pedrinho A. Guareschi. Petrópolis: Vozes, 2000. p. 271-292.

RATNER, Carl. Analysing cultural-psychological themes in narrative statements. Forum: Qualitative Social Research, Budapest, v. 2, n. 3, p. 1-8. Disponível em: <www.qualitative-research-net>. Acesso em: 17 jan. 2005.

RIBEIRO, Julia Cristina Coelho. Significações na escola inclusiva: um estudo sobre as concepções e práticas de professores envolvidos com a inclusão escolar. Tese (doutorado). Instituto de Psicologia Universidade de Brasília, 2006.

SANTOS, Paulo França. Hospital e escola: a construção do conhecimento sobre a criança deficiente. Dissertação (mestrado). Instituto de Psicologia. Universidade de Brasília. 2000.

SILVA, Rosalina Carvalho. A falsa dicotomia qualitativo-quantitativo: Paradigmas que informam nossas práticas de pesquisa. In: ROMANELLI, Geraldo; BIASOLI-ALVES, Zélia Maria Mendes (Orgs.), Diálogos metodológicos sobre prática de pesquisa. Ribeirão Preto: Legis Summa, 1998. p. 159-174. 
VALSINER. Jaan. The promoter sign: developmental transformation within the structure of dialogical self. Trabalho apresentado no Simpósio Developmental aspects of the dialogical self (Hubert Hermans, Convener). ISSBD, Gent, Bélgica, jul. 2004.

; BRANCO, Ângela Uchoa; DANTAS, Cristina. Socialization as co-construction: parental belief orientations and heterogeneity of reflection. In: GRUSEC, Joan; KUCZYNSKY, Leon (Orgs.), Parenting and children's internalization of values, New York: Wiley, 1997. p. 283-306.

VIGOTSKI, Liev Semionovitch. Pensamento e linguagem. São Paulo: Martins Fontes, 1989.

Fundamentos de defectologia: obras completas. Tomo cinco. Ciudad de La Habana:

Editorial Pueblo y Educación, 1995. . A formação social da mente. São. Paulo: Martins Fontes, 1998.

VOLOSINOV, Valetin Nicolaevich. Marxismo e filosofia da linguagem. São Paulo: Hucitec, 1992. WERTSCH, James. Voces de la mente: un enfoque sociocultural para el estudio de la acción mediada. Madrid: Visor, 1993. 


\section{Conception of teachers on school inclusion of students with neuromotor disorders}

\section{Abstract}

The identification and analysis of the conceptions of teachers on school inclusion of students with neuromotor disorders was attempted in this article. Twelve teachers from regular schools participated in the semi-structured interviews conducted individually by a hospital professor on the learning process of students with neuromotor disorders. The data were taped, transcribed and then submitted to a thematic dialogical analysis, thus allowing for a comprehension of the enunciates. The conceptions of the teachers focused on the themes: a) diagnostic; b) treatment; c) development and learning. Significances denoting the collision between old and new models of development and learning of students with special needs were enunciated. The results indicated that, according to the participants, the relation of cooperation established between regular and hospital teachers collaborated to the comprehension of school inclusion of their students as well as the clarification of doubts and questions about diagnostics, treatment and mediations.

Keywords: School inclusion. Conceptions of teachers. Rehabilitation. Hospital teachers. Neuromotor disorders.

\section{La conception de maîtres sur l'inclusion des élèves avec des déficiences neuromotrices Résumé}

Dans cet article l'on a tenté d'identifier et d'analyser les conceptions de maîtres sur l'inclusion d'elèves avec des déficiences neuromotrices. Douze maîtres provenant d'écoles régulières ont participé dans des entrevnes semi-structurées conduites individuellement par un professeur hospitalier sur le processus d'apprentissage d'élèves avec des déficiences neuromotrices. Les données ont été enregistrées, transcrites et ensuite soumises à une analyse thématique dialogique qui a permit une compréhension des énoncés. Les conceptions des maîtres ont focalisé sur les thèmes suivants: a) diagnostique; b) traitement; c) développement et apprentissage. Des signifiants ont été énoncés dénotant la collision entre les nouveaux et les vieux modèles de développement et d'apprentissage d'étudiants avec des besoins spéciaux. Les résultats ont indiqué que, selon les participants, la relation de coopération établie entre les maîtres réguliers et les maîtres hospitaliers a aidé à la compréhension de l'inclusion scolaire de leurs étudiants bien comme a clarifié des doutes et répondu aux questions au sujet de diagnostiques, traitement et médiations. Mots clefs: Inclusion scolaire. Conceptions de maîtres. Réhabilitation. Maîtres hospitaliers. Déficiences neuromotrices.

\section{Concepciones de profesores sobre la inclusión escolar de alumnos con disfunciones neuromotoras}

\section{Resumen}

Se buscó en este trabajo identificar y analisar las concepciones de profesores sobre la inclusión escolar de alumnos con disfunciones neuromotoras. Doce profesores de escuelas regulares participaron de entrevistas semiestructuradas individuales conducidas por un profesor hospitalar acerca del proceso enseñanza-aprendizaje de alumnos con disfunciones neuromotoras. Los datos, grabados y transcritos, fueron sometidos a un análisis temático dialógico permitiendo la comprensión de las enunciadas. Las concepciones de los profesores focaron los temas: a) diagnóstico; b) tratamiento; c) desarrollo-aprendizaje. Fueron enunciados significados denotando el embate entre modelos antiguos y nuevos sobre desarrollo y aprendizaje de alumnos con necesidades especiales. Los resultados indicaron que, según los participantes, la relación de cooperación establecida entre los profesores regulares y el hospitalar contribuye para la comprensión del proceso de inclusión escolar de sus alumnos, bien como el esclarecimiento de dudas y cuestiones sobre diagnósticos, tratamientos y mediaciones.

Palabras-clave: Inclusión escolar. Concepciones de profesores. Reabilitación. Profesores hospitalares. Disfunciones neuromotoras. 
